\title{
Capsule Commentary on Perlman et al., Efficacy and Safety of Massage for Osteoarthritis of the Knee: a Randomized Clinical Trial
}

\author{
Jeffrey L. Jackson, MD MPH
}

Zablocki VAMC, Milwaukee, USA

J Gen Intern Med 34(3):444

DOI: $10.1007 / \mathrm{s} 11606-018-4803-1$

(c) Society of General Internal Medicine (This is a U.S. government work and not under copyright protection in the U.S.; foreign copyright protection may apply) 2019

$\mathrm{K}$ nee pain is a common reason patients seek attention in primary care ${ }^{1}$, though clinicians often feel unprepared to deal with $i t^{2}$. This is the tip of the iceberg as patients often manage knee pain at home without seeking medical advice ${ }^{3}$. Pharmacologic treatment has only limited benefit. In their trial, Perlman and colleagues evaluated the efficacy of massage therapy in managing knee osteoarthritis (OA). They randomized patients with chronic knee OA to usual care, light touch or whole body Swedish massage weekly for 8 weeks, then every other week for 52 weeks ${ }^{4}$. They found improvement in several knee pain parameters over the initial 8 weeks, while the patients received weekly massage, but by 52 weeks, maintenance (biweekly) massage was no better than usual care. This is particularly interesting because patients were presenting with chronic, not acute, knee pain. As the authors point out, "the underlying mechanisms of massage-mediated improvements in osteoarthritis are not well-defined, preliminary studies suggest that massage may improve systemic immune and inflammatory profiles." This seems a good place for research effort, elucidating the mechanism for potential benefit from Swedish massage.

What is not clear from this study is whether weekly Swedish massage might lead to sustained improvement. The improvement appears to last for the 8 weeks that weekly massage was being provided; after that, having a massage every other week appears to not be therapeutic. A recent review of nonpharmacologic treatment found that weight loss and exercise are the only interventions with strong evidence of longterm benefit on knee pain and that other approaches had weak evidence for short-term benefit only ${ }^{5}$. A common problem is that trials were either too short or too low quality to provide good evidence of efficacy. This study is a good example of the rigorous approach that needs to be incorporated to obtain strong evidence for benefit from CAM options.

Corresponding Author: Jeffrey L. Jackson, MD MPH; Zablocki VAMC, Milwaukee, USA (e-mail: jjackson@mcw.edu).

Publisher's Note: Springer Nature remains neutral with regard to jurisdictional claims in published maps and institutional affiliations.

\section{REFERENCES}

1. Jackson JL, O'Malley PG, Kroenke K. Evaluation of acute knee pain in primary care. Ann Intern Med. 2003 Oct 7;139(7):575-88.

2. Battiston MJ, Barker AM, Grotzke M, Beck JP, Lawrence P, Cannon G. Mini-Residency in Musculoskeletal Care: a National Continuing Professional Development Program for Primary Care Providers J Gen Intern Med. 2016 31(11): 1301-1307.

3. Mitchell HL, Carr AJ, Scott DL. The management of knee pain in primary care: factors associated with consulting the GP and referrals to secondary care. Rheumatology (Oxford). 2006 Jun;45(6):771-6.

4. Perlman A, Fogerite SG, Glass O, Bechard E, Ali A, Njike V, Pieper C, Dmitrieva NO, Luciano A, Rosenberger L, Keeer T, Milak C, Finkelstein E, Mahon G, Campanile G, Cotter A, Katz D. Efficacy and Safety of Massage for Osteoarthritis of the Knee: A Randomized Clinical Trial. J Gen Intern Med. (https://doi.org/10.1007/s11606-018-4763-5).

5. Newberry SJ, FitzGerald J, SooHoo NF, Booth M, Marks J, Motala A, Apaydin E, Chen C, Raaen L, Shanman R, Shekelle PG. Treatment of Osteoarthritis of the Knee: An Update Review [Internet]. Rockville (MD): Agency for Healthcare Research and Quality (US); 2017 May Report No.: 17-EHC011-EF.

Published online January 4, 2019 